\title{
DISMANTLING THE RHETORIC OF ALTERNATIVE MEDICINE SMOKESCREENS, ERRORS, CONSPIRACIES, AND FOLLIES
}

EdZARD ERnST AND ANGELo FASCE

Alternative medicine has a high social prevalence, being promoted by well organized groups that have developed an intricate rhetoric in order to self-justify in the absence of evidence. This article will analyse some of these arguments, some of their fallacies - ad populum, ad ignorantiam-, other styles of reasoning - conspiracy theories - and other misconceptions of scientific concepts - placebo effect, scientific authority. The objective will be to highlight the poverty of the rhetoric of proponents of alternative medicine, with special emphasis on the dangers for the consumer.

Keywords: alternative medicine, fallacies, pseudoscience, argumentation.

Alternative medicine is infested by illogical thinking. If one talks to acupuncturists, homeopaths, herbalists, chiropractors or other types of alternative practitioners, or studies the many articles on the subject, or listens to patients of alternative healthcare providers, critical thinkers are bound to find that fallacies and weird thoughts abound. You may be wondering: what is alternative medicine? Is there an alternative to medicine? The answer to the second question is «no», the answer to the first one is somewhat more complex. What we usually call «alternative medicine», and which some studies on the subject call «CAM» (Complementary and Alternative Medicine), is a set of practices that are offered to society as having the healing effects of evidence-based medicine, but without having proven its effectiveness - when alternative medicine proves its effectiveness, it is renamed as «medicine». The differential factor between both practices lies in the epistemic warranty that each one of them has and in the warranty they can offer to their users.

CAM includes chiropractic, reiki, Bach flowers, reflexology, acupuncture, aromatherapy, kinesiology, Ayurveda, Tibetan, quantum or anthroposophical medicines, in some cases with sectarian features and focused in very specific diseases, such as cancer. Examples of these latter cases are the new German medicine and its offspring, like biodescodification or the Spanish bioneuroemoción. Although all are presented as healing techniques, some are more pseudoscientific and others more related to paranormal thinking. For example, the reasons why more than half of Spaniards trust in homeopathy (Fundación Española para la Ciencia y la Tecnología [FECYT], 2017) - they also consider it as more scientific than economics (FECYT, 2015) - should be different from those of users of prayer healing, since homeopathy meets the requirements for being a pseudoscience in a much more explicit way, and their rhetoric should differ (Blancke, Boudry, \& Pigliucci, 2017; Hansson, 2009).

Despite the public complaints of skeptical associations based on the ethical and evidential deficiencies of CAM, in addition to the constant cases of victims of pseudotherapies or the re-emergence of previously eradicated diseases, its social prevalence is very high. The European Union carried out a project to study the phenomenon among its countries: 145,000 physicians use CAM, there are 160,000 CAM practitioners outside professional medicine, with 
about 65 CAM practitioners per 100,000 inhabitants compared to the 95 medical practitioners for the same amount, and about $30 \%$ of the European population uses these techniques frequently (CAMbrella, 2012). The Spanish government carried out its own study, in which it was estimated that $23 \%$ of Spaniards consume alternative medicine (Ministerio de Sanidad, Política Social e Igualdad, 2011), a lower number than the European report, which raised it up to $31 \%$ for this specific country (CAMbrella, 2012). The most used techniques in Spain are yoga, acupuncture, chiromassage and homeopathy (the Spanish report includes a list of 139 CAM techniques with their respective explanations, something that may be interesting to the reader).

In the following lines, we will analyse much of the discourse of proponents of alternative medicine (PAMs). Their rhetoric, the arguments used by PAMs to convince the public, constitutes a set of characteristics that allow us to detect medical fraud wherever it is, since the rhetoric of science, based on prudence and solid evidence, is radically different. Rhetoric is the art of convincing, and for certain people in the art of convincing anything goes. Some of these arguments are formal fallacies, other are informal fallacies and other are thinking tendencies - such as conspiracy theories - but they all point out that we should not put our health in the hands of its defenders.

\section{APPEAL TO POPULARITY}

PAMs continuously tell us that, if millions use a certain therapy, it can safely be assumed that it is effective and risk-free - a prime example of what is known in argumentation theory as the ad populum fallacy. This fallacy ignores the fact that a belief can be wrong; even if followed by many people, a practice, habit or tradition can still be misguided. The popularity of a therapy is certainly not a reliable barometer of its effectiveness. The history of medicine is littered with examples demonstrating how dangerous this fallacy can be. Bloodletting, purges, and mercury cures were all, at one time or another, widely practiced and believed to be effective - and yet these treatments undoubtedly killed more patients than they ever cured. If we followed the logic of PAMs and allowed medicine to degenerate into a popularity contest, we jeopardize all the remarkable achievements that have been made in the last 150 years.

But this is a very common marketing strategy for some companies like Boiron who, instead of appealing to an evidence that does not exist (Mathie et al., 2017), appeal to the level of satisfaction of consumers of

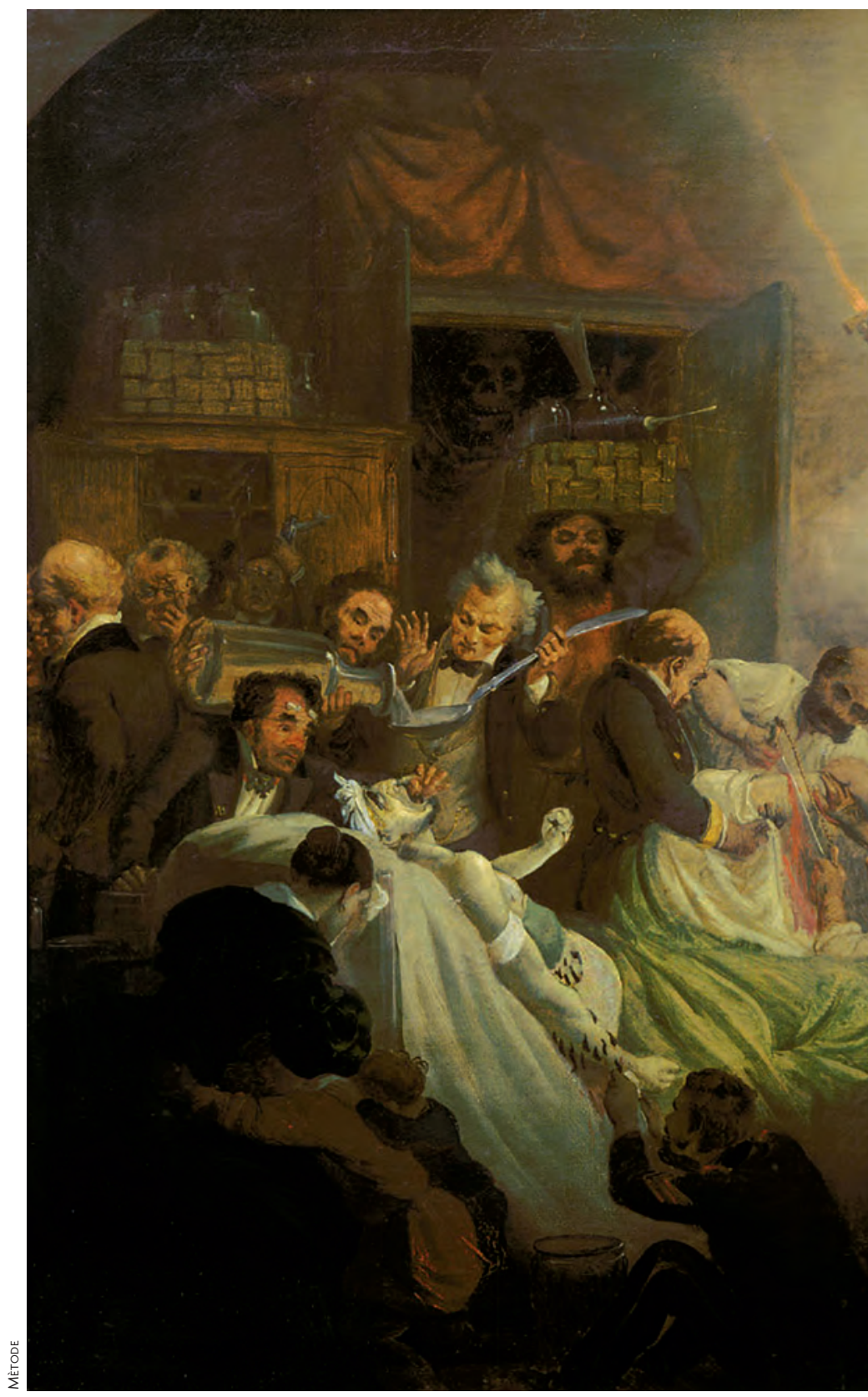

Alexander Beideman. Homeopathy watching the horrors of allopathy, 1857. Oil on canvas, $77 \times 65 \mathrm{~cm}$. A particularly seductive argument from advocates of alternative medicine is that it is more compassionate than conventional medical care. 


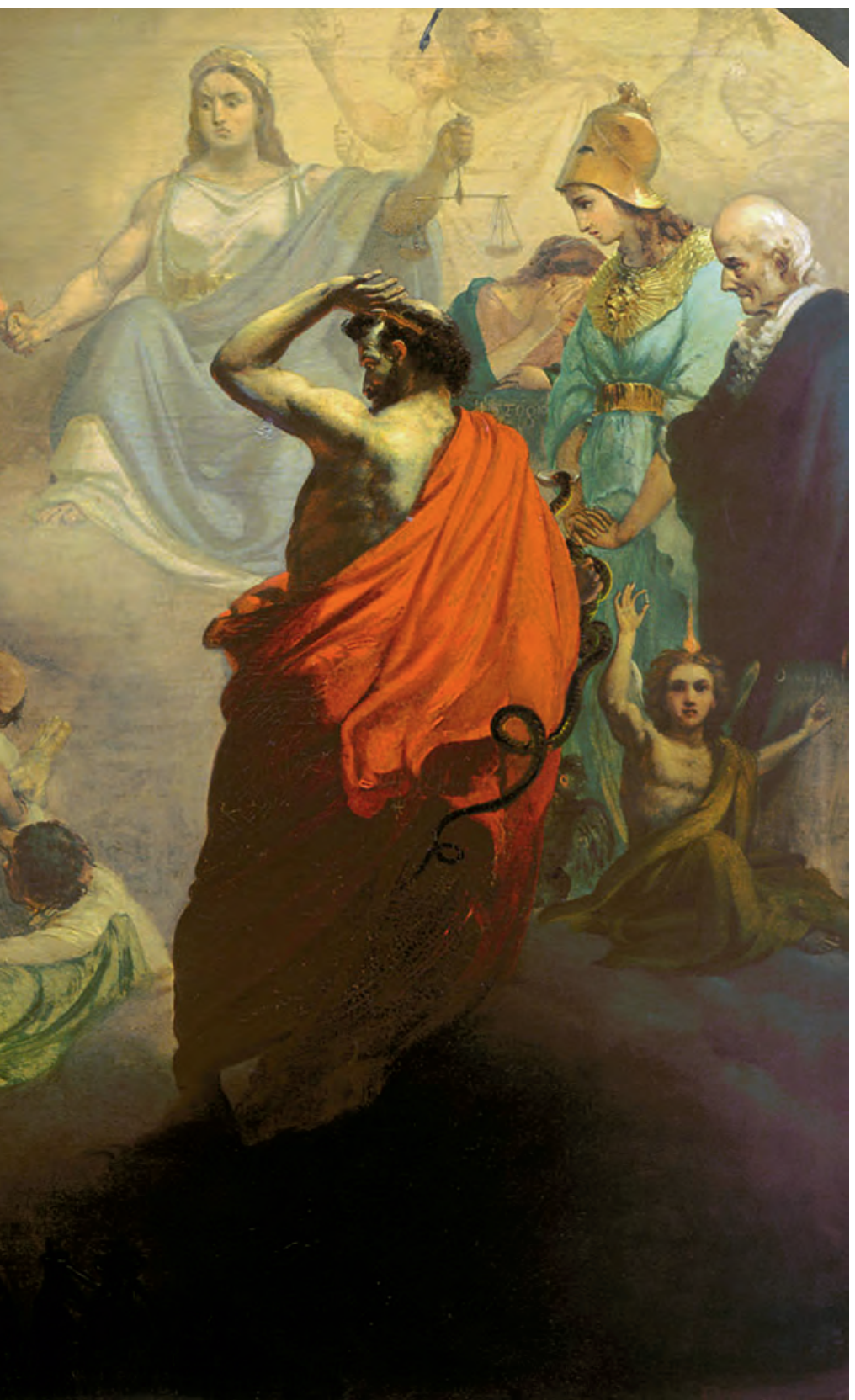

«THE POPULARITY OF A THERAPY

IS CERTAINLY NOT A RELIABLE BAROMETER OF ITS EFFECTIVENESS» homeopathy. «Eight out of ten (82\%) people using homeopathy are satisfied or very satisfied with the outcome of their treatments, and this figure grows up to $99 \%$ in regular patients. In addition, if we take into account that $87 \%$ of the users would recommend it to relatives and friends, future can't be any brighter» is said in an article with a clear conflict of interests - the authors are Boiron employees (Díaz, Moreno, \& Balmy, 2012). Are these reliable results? Certainly not. Are these real results? Who knows. «Being satisfied» is not synonymous with having received a good medical treatment. Are these relevant results that should make us evaluate the possibility of consuming homeopathy? No, they are not; medicine is not a democracy.

Many forms of alternative medicine have a long history, and PAMs use this fact to convince the public of their value. Any treatment that has passed the test of time, they say, must be effective and safe. After all, people are not stupid; why would they persist in using such treatments, if they did not work or cause

\section{"THE ADMINISTRATION OF PLACEBOS TO ILL PATIENTS CAN BE BOTH UNETHICAL AND DANGEROUS»}

harm? Some PAMs even view the «test of time» as significantly more relevant than any objective evaluation of therapeutic effectiveness. A long history of use is therefore a more conclusive test than science can ever provide. But to promote wider acceptance of their therapy, PAMs not only invoke opinions and history, they often invoke the support of authority. They may, for instance, state that a national health service endorses their particular modality; or that, in China, acupuncture is supported by the government; or that a respected nationwide pharmacy chain sells their products; or that the Royal family or some other celebrities use this treatment; or that Nobel Prize winners support it, etc.

These claims might well be true, but one cannot infer from them that the treatment in question must therefore be valuable. The fact that any person or institution, however well respected, praises or adopts something might merely illustrate that even well educated people or powerful institutions can sometimes commit the silliest and most obvious of mistakes. Science is not elitist regarding clumsiness. WHO has accepted reiki as a valid medical intervention in some documents, for example for 
pain relief in patients with AIDS (World Health Organization, 2001). Reiki has no evidence for the treatment of pain beyond the placebo effect (Lee, Pittler, \& Ernst, 2008), and this case constitutes a harmful lack of scientific standards in the WHO technicians. But even if we can criticize their decision, reiki is in a WHO document, and that is what matters for PAMs.

\section{THE WICKEDNESS OF EVIDENCE-BASED MEDICINE}

When PAMs cannot avoid conceding that their treatment is ineffective, they usually insist that this does not really matter. Per this fuzzy line of reasoning, the mechanism of the effect is of secondary importance; the only thing that truly counts is to help the patient by whatever means one can. Superficially, the assumption sounds logical and compassionate. Yet it ignores several important points. The administration of placebos to ill patients can be both unethical and dangerous. Some forms of alternative medicine are by no means inert but can cause serious adverse effects (Niggeman \& Grüber, 2003). Pneumothorax and infections are the most frequently reported adverse effects of acupuncture (Ernst, Lee, \& Choi, 2011). Also, harmful interactions exist between herbal medicines and prescribed drugs (Izzo \& Ernst, 2009), or harm due to the components of those herbal medicines (Posadzki, Watson, \& Ernst, 2009). The lack of control of traditional and herbal medicines are also a serious risk for ecosystems, because of the possible introduction of illegal components and also due to the hunting of endangered animals (Byard, 2016; Byard, Musgrave, Maker, \& Bunce, 2017).

Moreover, to elicit a placebo response, it is not necessary to administer a placebo. If a clinician gives his patient an effective treatment with empathy and compassion, he will generate a placebo response in addition to the response to the effective treatment he has chosen for his patient. Only giving a placebo therefore deprives the patient of the benefits of a treatment that has specific therapeutic effects. In other words, the administration of placebo therapies would normally mean cheating the patient out of something that would contribute importantly to his recovery - and this, surely, is not only unethical but also potentially harmful.

A particularly seductive argument for PAMs is that alternative medicine is intrinsically more compassionate than conventional medical care.

\section{$\equiv$ ELPAIS \\ Los antivacunas franceses preparan una demanda colectiva contra las farmacéuticas}

Una asociación intenta resucitar el bulo que relaciona inmunización con autismo. Uno de cada dos ciudadanos se opone a la vacunación obligatoria anunciada por el Gobierno

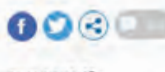

gitruinuso 5
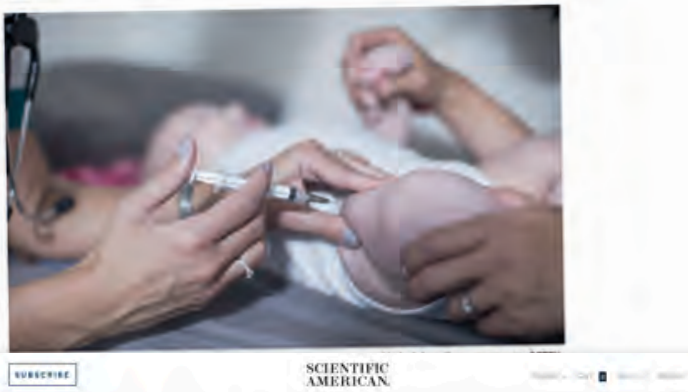

Fact or Fiction?: Vaccines Are Dangerous

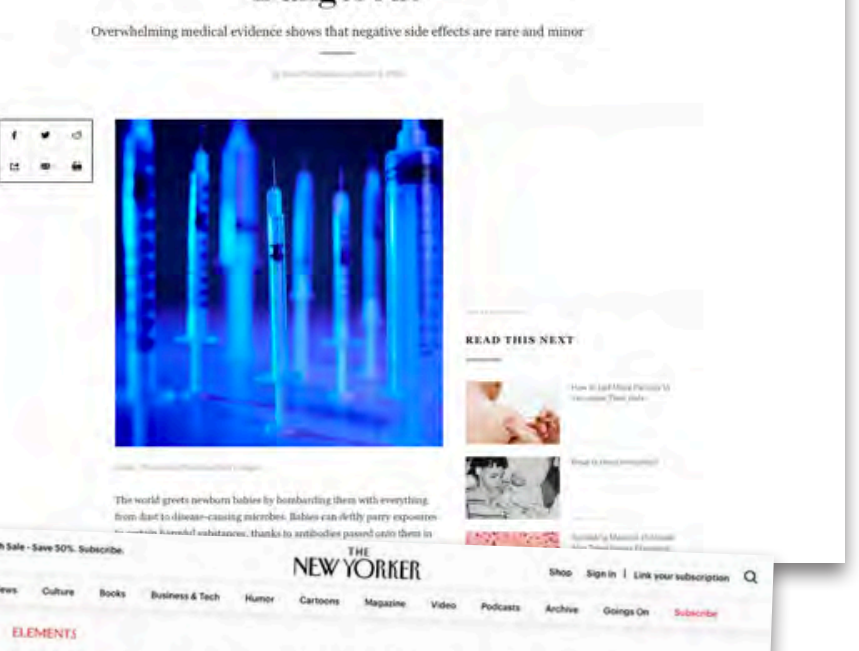

TRUMP'S DANGEROUS SUPPORT FOR CONSPIRACIES ABOUT AUTISM AND VACCINES

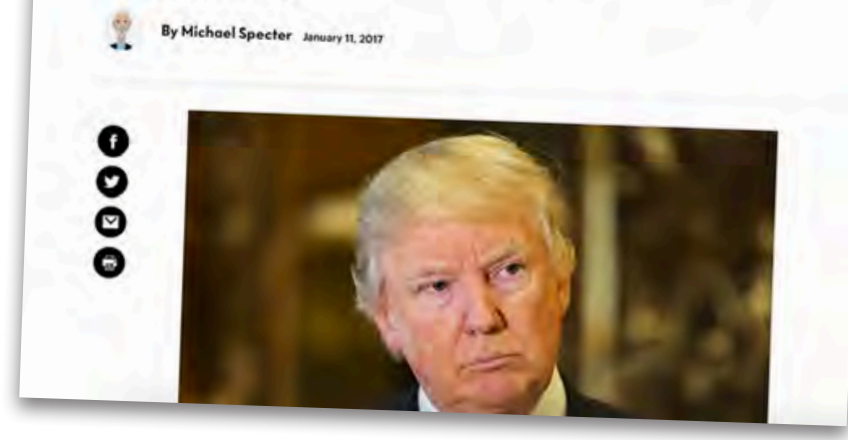

Conspiracies are typical of scientific denialism. A good example is the case of the antivaccination movement, which often blame a conspiracy between pharmacists, doctors and the government to hide the dangers of vaccination. 
This argument has instant resonance with a public that is all too familiar with the harried physician whose time is always limited and who often does a less than perfect job of answering questions and anticipating patients' concerns. It is true that many alternative practitioners are full of good intentions and often manage to cultivate a friendly and empathetic therapeutic relationship with their patients which may well have useful potential. However, to extrapolate from this fact that alternative therapies are effective or useful, is little more than a self-serving delusion. There is nothing intrinsically heartless about conventional medicine, nor does alternative medicine have a uniquely gentle, caring ethos. Compassion, empathy and good patient-clinician interactions are not the exclusive purview of any branch of medicine. On the contrary, they are the hallmarks of any good healthcare, whatever its philosophical, ideological or therapeutic orientation.

\section{GETTING RID OF THE BURDEN OF PROOF}

One of the main principles of logic and theory of confirmation is the burden of proof (Pigliucci \& Boudry, 2014). Burden of proof is in the basis of probabilistic - Bayesian - reasoning and refers to who must provide the evidence. Despite the epistemological complications of the concept, we must ask for evidence to whoever is proposing the existence of an entity or process, rather than ask, at least in the first place, for evidence to whoever is denying its existence - this is why we don't believe in fairies and unicorns. In healthcare, it is unwise, dangerous and arguably unethical to give the benefit of the doubt to under-researched therapies. In the best interest of patients, we should employ only treatments that are supported by sound evidence. This means that we must consider all interventions to be ineffective and unsafe until sound data to the contrary are available. Yet many PAMs like to stress that the absence of evidence of an effect does not constitute evidence of the absence of an effect - aka fallacy of argument from ignorance. In other words, just because we have no evidence on the effectiveness or safety of a given type of alternative medicine, we cannot simply assume that it is ineffective or unsafe.

The principle is, of course, theoretically correct: we have not identified life on other planets, for instance, but we cannot be sure that no extraterrestrial life exists. However, the conclusion some

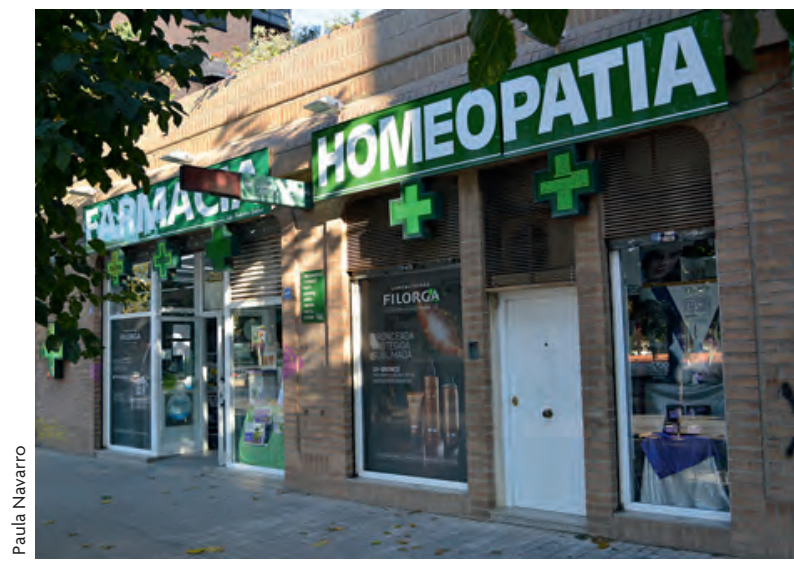

Advocates of alternative medicine often use authority as well. For example, they may argue that a particular national health service supports their specific model or that a respected national pharmacy franchise sells their products.
PAMs draw from this principle is fallacious. They like to argue that it is reasonable or in the best interest of patients to continue using the treatment in question (Ben-Arye, Frenkel, Klein, \& Scharf, 2008). Intriguingly, the people using this argument are usually the quickest to decry scientists' attempts to evaluate the very methods that they espouse so passionately. Far from decreasing the total number of non-evidence based therapies in routine care, this approach would dramatically increase it. If we identify treatments as being unproven, we have a duty to test them; and until the results are in, we should hesitate using them in clinical routine, and this is precisely what is happening in evidence-based medicine.

Another version of this argument, this time as a tu quoque fallacy, alludes to the fact that one of the most frequent causes of illness is the harm caused by conventional treatments, particularly prescription drugs. In comparison to the number and seriousness of adverse effects attributable to prescription drugs, so the argument goes, those caused by alternative medicine are vanishingly small. The implication here is, of course, that researchers should just stop worrying people with their concerns about the safety of some alternative therapies. It is undoubtedly correct that the risks of some conventional treatments are far greater than those of most alternative therapies: chemotherapy has more side effects than aromatherapy, for instance. But this is merely a platitude and entirely beside the point. The value of a 


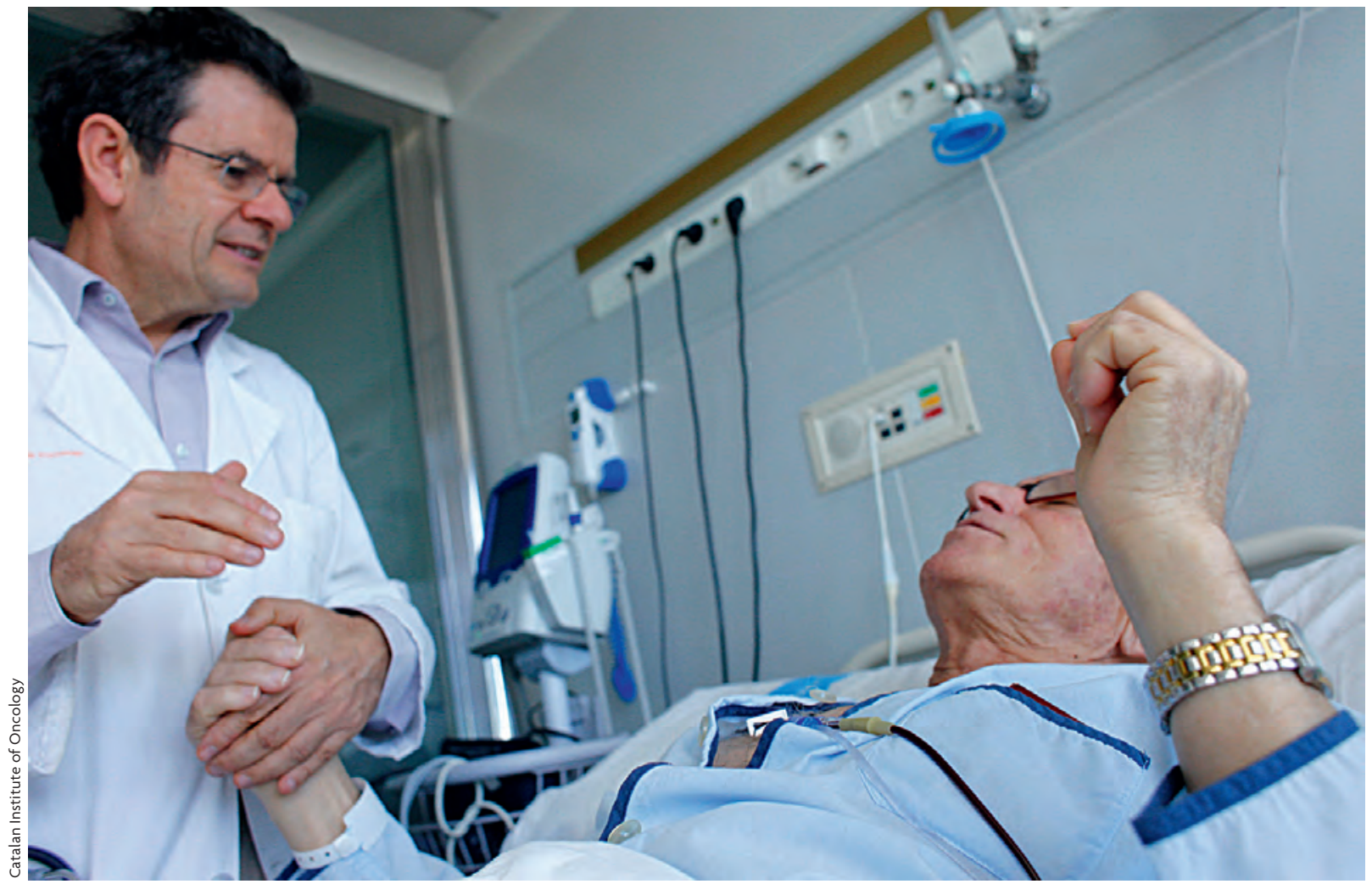

The risks of some conventional treatments are much greater than most alternative therapies. But if a more aggressive treatment can potentially save lives, as is the case with chemotherapy, even substantial risks are outweighed by the potential benefit.

treatment is not determined by its absolute risk but by the balance between risk and benefit. If a treatment is potentially life-saving, such as chemotherapy, even substantial risks will be offset by the benefit to be gained. If, however, a therapy has no, or very little proven benefit - which is the case with many alternative treatments - even a small risk must weigh heavily.

\section{CONSPIRACY THEORIES}

Irrational worldviews often include a hefty component of paranoia. A conspiracy theory can be defined as a lay belief that attributes the ultimate cause of an event, or the concealment of an event from public knowledge, to a secret, unlawful, and malevolent plot by multiple actors working together. These kind of theories and persecution complexes are the preferred way of some PAMs to explain why mainstream medicine continues to ignore their anointed approach to healthcare. With unfailing regularity, PAMs claim that powerful forces are at work to suppress their time-honoured wisdom. The pharmaceutical industry - Big Pharma-is almost invariably implicated as the chief villain in this context. The fevered plot has it that the pharmaceutical industry is systematically sabotaging alternative medicine because it would lose substantial amounts of revenue, if the true value of alternative medicine were to become general knowledge. Conspiracies are typical of science denialism. For example, vaccines or AIDS denialism have a big conspiratorial component (Jolley \& Douglas, 2014; Lewandowsky, Gignac, \& Oberauer, 2013).

Of course, conspiracies do occur, but this interpretation of the events becomes a serious problem when it turns into a maladaptive worldview (Dagnall, Drinkwater, Parker, Denovan, \& Parton, 2012), and PAMs ever produce good evidence to substantiate it. Many sections of the pharmaceutical industry are barely aware of the alternative medicine industry. Other sections find ways of profiting from it, for example by marketing «natural» dietary supplements. Next to the arch-villain Big Pharma, the medical profession comes a close second. Oncologists in particular are singled out as ruthless conspirators, single-mindedly suppressing alternative cancer «cures». Yet, no oncologist would not be delighted to have access to further effective cancer cures regardless of whether they originated from the field of alternative medicine or from any other source. 


\section{A FINAL COMMENT ON FALSE BALANCE}

We live in times where political correctness regularly drives us to look for the middle ground in areas where there simply is none. Journalists are particularly apt to kowtow to ideological orthodoxy in this way. For example, a health journalist writing an article about homeopathy might diligently present all the facts about the implausibility of the rationale on which homeopathy is based, and the lack of evidence to suggest that it has consistent, replicable value in the treatment of illness. But, obedient to the zeitgeist of cultural relativism, the journalist would also feel obliged to balance this with input from the «other side» - i.e., with quotes from a homeopath who says that science cannot know everything and his personal experience is more important than scientific data. This would, of course, be fair enough, provided there were a reasonable «other side» whose arguments had weight and substance. If, however, the «other side» is not of equivalent substance, this insistence on balance creates the erroneous impression that there is a continuing, valid scientific debate between two equal hypotheses, while, in fact, the science has long been settled. The discussion as to whether the Earth is flat or a sphere is as closed as the one concerning homeopathy and several other areas within alternative medicine. Imagine that National Geographic were to publish an article «balancing» existing scientific knowledge by presenting the opinions of a member of the Flat Earth Society. Who would take it seriously? Yet we accept regularly the equivalent when discussing alternative medicine. $\odot$

\section{REFERENCES}

Ben-Arye, E., Frenkel, M., Klein, A., \& Scharf, M. (2008). Attitudes toward integration of complementary and alternative medicine in primary care: Perspectives of patients, physicians and complementary practitioners. Patient Education and Counseling, 70(3), 395-402. doi: 10.1016/j. pec.2007.11.019

Blancke, S., Boudry, M., \& Pigliucci, M. (2017). Why do irrational beliefs mimic science? The cultural evolution of pseudoscience. Theoria, 83(1), 78-97. doi: 10.1111/theo.12109

Byard, R. W. (2016). Traditional medicines and species extinction: Another side to forensic wildlife investigation. Forensic Science, Medicine and Pathology, 12(2), 125-127. doi: 10.1007/s12024-016-9742-8

Byard, R. W., Musgrave, I., Maker, G., \& Bunce, M. (2017). What risks do herbal products pose to the Australian community? The Medical Journal of Australia , 206(2), 86-90. doi: 10.5694/mja16.00614

CAMbrella. (2012). CAMbrella documents and reports. Retrieved from http://www.cambrella.eu/home.php?il=203\&l=deu

Dagnall, N., Drinkwater, K., Parker, A., Denovan, A., \& Parton, M. (2015). Conspiracy theory and cognitive style: A worldview. Frontiers in Psychology, 6, 2-9. doi: 10.3389/fpsyg.2015.00206
Díaz, G., Moreno, G., \& Balmy, S. (2012). Estudio sobre conocimiento y uso de homeopatía en España. Revista de Medicina Homeopática, 5(3), 113-119. doi: 10.1016/S1888-8526(12)70157-1

Ernst, E., Lee, M. S., \& Choi, T. Y. (2011). Acupuncture: Does it alleviate pain and are there serious risks? A review of reviews. Pain, 152(4), 755764. doi: 10.1016/j.pain.2010.11.004

Fundación Española para la Ciencia y la Tecnología. (2015). VII Encuesta de percepción social de la ciencia. Madrid: FECYT. Retrieved from http://www.idi.mineco.gob.es/stfls/MICINN/Prensa/NOTAS_ PRENSA/2015/Dossier_PSC_2015.pdf

Fundación Española para la Ciencia y la Tecnología. (2017). VIII Encuesta de percepción social de la ciencia. Madrid: FECYT. Retrieved from http://www.idi.mineco.gob.es/stfls/MICINN/Cultura/ FICHEROS/2017/Dossier_PSC 2017.pdf

Hansson, S. O. (2009). Cutting the Gordian knot of demarcation. International Studies in the Philosophy of Science, 23(3), 237-243. doi: $10.1080 / 02698590903196007$

Izzo, A., \& Ernst, E. (2009). Interactions between herbal medicines and prescribed drugs. An updated systematic review. Drugs, 69(13), 17771798. doi: 10.2165/11317010-000000000-00000

Jolley, D., \& Douglas, K. (2014). The effects of anti-vaccine conspiracy theories on vaccination intentions. PLOS ONE, 9(2), e89177. doi: 10.1371/journal.pone.0089177 Lee, M. S., Pittler, M., \& Ernst, E. (2008). Effects of reiki in clinical practice: A systematic review of randomised clinical trials. The International Journal of Clinical Practice, 62(6), 947-954. doi: 10.1111/j.17421241.2008.01729.x

Lewandowsky, S., Gignac, G., \& Oberauer, K. (2013). The role of conspiracist ideation and worldviews in predicting rejection of science. PLOS ONE, 8(10), e75637. doi: 10.1371/journal.pone.0075637

Mathie, R. T., Ramparsad, N., Legg, L. A., Clausen, J., Moss, S., Davidson, J. R., ... McConnachie, A. (2017). Randomised, double-blind, placebocontrolled trials of non-individualised homeopathic treatment: Systematic review and meta-analysis. Systematic Reviews, 6(1), 63. doi: 10.1186/ s13643-017-0445-3

Ministerio de Sanidad, Política Social e Igualdad. (2011). Análisis de situación de las terapias naturales. Retrieved from https://www.msssi. gob.es/novedades/docs/analisisSituacionTNatu.pdf

Niggemann, B., \& Grüber, C. (2003). Side-effects of complementary and alternative medicine. Allergy, 58(8), 707-716. doi: 10.1034/j.13989995.2003.00219.x

Pigliucci, M., \& Boudry, M. (2014). Prove it! The burden of proof game in science vs. pseudoscience disputes. Philosophia, 42(2), 487-502. doi: 10.1007/s11406-013-9500-z

Posadzki, P., Watson, L., \& Ernst, E. (2009). Adverse effects of herbal medicines: An overview of systematic reviews. Journal of the Royal College of Physicians, 13(1), 7-12. doi: 10.7861/clinmedicine.13-1-7

World Health Organization. (2001). Atención integral por escenarios de atención y niveles: Pautas de atención integral para personas que viven con VIH/SIDA en las Américas. Retrieved from http://wwwl.paho.org/ Spanish/AD/FCH/Al/BB_Summary_span.pdf

Edzard Ernst. Emeritus professor of Complementary Medicine at the University of Exeter (United Kingdom). His professional research has focused on obtaining evidence and verified information on these practices. He has published more than 1,000 articles in specialized medical journals, more than 100 chapters in books, and 50 of his own works (the latest of which is Homeopathy. The undiluted facts, Springer, 2016). He has received numerous awards for his work in popularization, such as the John Maddox Prize awarded by the Kohn Foundation and Nature magazine.

Angelo Fasce. Philosopher of science with a neuroscience background. He is currently a doctoral student at the Department of Philosophy in the University of Valencia (Spain). He is an expert on the demarcation problem and the psychological mechanisms that give rise to irrational thinking. $\mathrm{He}$ is also an active disseminator of science and its philosophy. 